\title{
Drug-motivated behavior: The effect of morning glory seeds on motor activity of chicks
}

DOUGLAS W' MATHESON, liniversity of the Pacific, Stockton, Calif. 952014 and JULIE THOMAS, University of Southern California, Los Angeles, Calif. 90007

Chicks exhibited a higher rate of motor activity in an open-field situation after ingesting moming glory seeds than did a control group that did not receive the seeds. It is felt the increased activity is due to the psychomimetic compounds contained in moming glory seeds.

Lysergic acid diethylamide (LSD-25) does not occur in nature but is prepared by semi-synthesis. The drug affects behavior in two basic ways. First, it acts as a predominant sympathetic nervous system stimulant and secondly, to a lesser extent, there is c central and peripheral depression. Morning glory seeds (Ipomoea) are known to contain certain alkaloids which are chemically similar to LSD-25 (Claus \& Tyler, 1965), the major one being d-lysergic acid amide (Rice \& Genst, 1965). Another alkaloid found in morning glory seeds is ergometrine, a known central nervous system stimulant. The ingestion of morning glory seeds facilitates a behavioral reaction very similar to that caused by LSD-25, and they have been used by both teenagers and adults to create visual hallucinations. One young woman who had taken 250 seeds felt very hyperactive, anxious, experienced an increased awareness of colors, and had a profound fear of losing her "mind." While under the influence of the seeds the woman had a rapid pulse and an accelerated respiration rate (Ingram, 1964). Rice \& Genest (1965) reported observing both motor dysfunction and death in mice given heavy doses of morning glory seed alkaloids.

The present experiment studied the effects of morning glory seed ingestion on general sympathetic activity in chicks by measuring motor activity under controlled conditions. It was predicted that motor activity of chicks would increase with the ingestion of morning glory seeds when activity was measured in an open-field situation.

\section{SUBJECTS}

Ten 3-day-old Leghorn rooster chicks (English st rain), weighing 3840 g each, were used in the experiment. All chicks were housed in a $30.5 \times 30.5 \mathrm{~cm}$ box which was kept in a warm, well lighted room. They were fed All-Age-Mash and given ad lib water in their home box.

\section{APPARATUS}

The activity testing apparatus was an open-field maze consisting of an enclosed rectangular cardboard box $(34.7 \times 44.5 \times 30.5 \mathrm{~cm})$ which was marked off into eight nearly square $13.8 \times 14.8 \mathrm{~cm}$ rectangles. Motor activity was measured by counting the number of rectangles crossed in a 3-min period. The chicks had to completely cross a line in order to get one activity count.

\section{PROCEDURE}

The 10 chicks were randomly assigned to two groups of five each, Group 1 serving as a control for Group 2. The two groups were separated in their home box by a partition and were provided with the same quantity of feed each day. Each chick was handled for 30 min on Day 1 and 10 min per day on 5 subsequent days (Days 2-6). Activity testing began on the third day of handling (Day 3). Each group was food deprived for $5 \mathrm{~h}$. At the end of the 5 -h period both groups were given access to food for $1 / 2 \mathrm{~h}$ and then were deprived of food for 2 additional hours. At the end of the 2-h period, each chick was placed individually in the open field testing apparatus where its spontaneous activity was measured by counting the number of rectangles traversed for $3 \mathrm{~min}$. The placement of the chick in the testing apparatus for $3 \mathrm{~min}$ was defined as a trial and all chicks received one trial. On Day 4 , the chicks were placed on the same deprivation schedule as Day 3. The procedure was the same except that during the $1 / 2-h$ feeding period each chick in Group 2 receive $0.123 \mathrm{~g}$ of mashed "Heavenly Blue" morning glory seed which was uniformly mixed with $2 \mathrm{~g}$ of their regular feed. All chicks consumed the mixture within the $1 / 2-h$ period. Group 2 was given the same amount $(2.123 \mathrm{~g})$ of their regular feed without the seeds. The procedure for Days 5 and 6 was the same as for Day 4. The deprivation schedule began at the same time of day for Days 3-6. At the end of a trial each chick was placed in a temporary box until all chicks in that group were tested. The chicks were then given food ad lib until the deprivation schedule started the next day.

\section{RESULTS AND DISCUSSION}

An analysis of the variance showed that Group 2's activity was significantly different from Group l's over days $[F(1,8)=7.095, p<.01]$. The analysis revealed that the activity of both groups changed over days. In addition, the linear component of the Group by Day interaction
Table 1

Mean Number of Rectangles Crossed per Day Each Mean is for $N \overline{\bar{T}} 5$ Chicks

\begin{tabular}{lccccc}
\hline & & \multicolumn{4}{c}{ Day } \\
& & 3 & 4 & 5 & 6 \\
Group & 1 & 1.6 & 3.0 & 4.0 & 11.4 \\
& 2 & 1.8 & 9.4 & 11.4 & 34.0 \\
\hline
\end{tabular}

was significant $[F(1,24)=9.24, p<.01]$, which suggested that Group 2's activity increased significantly faster than Group 1's. That is, the two linear components differ significantly. A $t$ test between activity measures of the two groups for Day 3 was not significant indicating that both groups' activity levels were initially the same. The mean number of rectangles crossed by each group for Days $3,4,5$, and 6 are shown in Table 1.

Although the control group (Group 1) did show a significant increase in activity over days, the rate of change was not as large as for Group 2. The increase in activity shown by Group 1 may be attributed to adaptation or to novel stimuli in the experimental apparatus (Montgomery, 1954). That is, as the animals moved about in the open field, they came into commerce with novel stimuli which elicited increased exploratory behavior.

The rate of activity of Group 2, being significantly greater than that of Group 1 , is attributed to the presence of alkaloids found in the seeds of the Heavenly Blue morning glory. Some of the components apparently can cause an increase in motor activity at a rate significantly greater than activity attributed to adaptation and novel stimuli alone. The results indicate that the drugs may have a cumulative effect on behavior. The agent or agents which facilitate the activity might be stored in the organism and could have a residual effect on subsequent days. Although there is no data for additional days, one might predict that the animals would have continued to increase their activity until severe motor dysfunction or death occurred.

In summary, morning glory seeds were found to increase motor behavior of chicks in an open-field situation. The increase in activity is in addition to activity attributed to adaptation or to novel stimuli. It also appears that the drug components in the seeds might have a cumulative effect on activity which could have a deleterious effect. 
REFERLNCES

ClAUS, E. P., \& TYLER, V. $\mathrm{l} .$, JR Pharmacognosy: (5 th ed.) Philadelphia: Lea \& Febiger, 1965.

INGRAM, A. L. Morning glory seed reaction. Journal of the American Medical Association, $1964,190,1133-1134$.
MONTGOMERY. k. C. The rok of the exploratory drive in learning. Joumal of Comparative \& Physiological Psy' chology, 1954 47,60 .

RICE, W. B., \& GENEST, K. Acute toxicity of extracts of morning-glory seeds in mice. Nature, $1965,207,302$.

\section{Aversive stimulation and reversal learning}

\begin{abstract}
JOHN J. OMALLEY' and JAMES L. BRUNING, Ohio Universitn, Athens, Ohio 4.5701
\end{abstract}

Albino rats were initially trained to make a black white discrimination to escape from high (.8 $\mathrm{mA}$ ) or low shock (.3 $\mathrm{mA})$. Reversal training was then begun either immediatel. after $S$ s reached an 8 out of 10 performance criterion or after 95 overtraining trials. Shock level did not affect performance in original training. There were no differences in trials-to-reversal criterion due to shock level or amount of prereversal training. However, as in appetitive situations, overtrained Ss made more consicutive perseverative errors following cue reversal, and showed less tendency to respond positionally during the first 24 reversal trials. Shock level did not affect perseveration or position responding.

In appetitive situations, overtraining on a brightness discrimination task tends to facilitate reversal learning while increasing the number of perseverative errors and reducing position-responding tendencies during early reversal learning (Mackintosh, 1962; Reid, 1953). In addition, level of motivation has been found to affect reversal learning. Kendler \& Lachman (1958) found that Ss run under $45-\mathrm{h}$ food deprivation during reversal training, took significantly longer to reverse a brightness discrimination than did Ss run under 3-h deprivation. The present study was designed to de termine the effects of amount of training and drive level on reversal learning in an escape situation.

\section{SUBJECTS AND APPARATUS}

Subjects were 36 female albino Holtzman rats, 90-120 days old at the beginning of the experiment. The apparatus was a T-maze, with a start box 12 in. long, a 24 -in. stem, and arms $14 \mathrm{in.} \mathrm{long.} \mathrm{The} \mathrm{height} \mathrm{and} \mathrm{width}$ of the apparatus were 6 in. and 4 in Guillotine doors were manually operated to separate the start box and the arms from the stem. The stem of the apparatus was painted flat grey; one of the arms was black, the other white. The arms could be alternated in order to make position cues irrelevant. The grid floor was electrified by an Applegate Model 250 stimulator connected to a Grason-Stadler grid scrambler.

\section{PROCEDURE}

In the first phase of the experiment, the $18 \mathrm{Ss}$ in the high $(.8 \mathrm{~mA})$ and low shock (. $3 \mathrm{~mA})$ were trained on a black-white discrimination to an 8-out-of-10 performance criterion. The black and white arms of the maze were alternated in a pseudorandom sequence so that each was on the left or right side for three of each block of six trials. After a correct response, which automatically terminated shock, S remained in the correct goal box for $20 \mathrm{sec}$. $S$ was allowed to retrace immediately after an incorrect response. Because of time demands. 16 Ss ( 8 from each shock level), which were responding at chance level after 80 trials, were discarded. The remaining $\mathrm{Ss}$ were then assigned to four groups of five each (high-shock, overtrained; high-shock, immediate reversal; low-shock, overtrained; low-shock, immediate reversal) in such a way that the mean original training scores of all groups were equated. Ss in the reversal groups began reversal training on the day after they reached the 8-out-of- 10 criterion, while overtrained Ss received 95 additional overtraining trials. The shock level was the same in original and reversal training. The reversal criterion was the same as during original training $(8$ out of 10 correct responses).

\section{RESULTS AND DISCUSSION}

Shock level had no effect on number of trials to original training criterion $(t=1.01$, $\mathrm{df}=18$ ). The means for the high- and low-shock groups were 58.4 and 52.6, respectively. An analysis of trials to reversal criterion data indicated no significant effects due to training or shock level, nor was the Shock by Training interaction significant $\quad[F(1,16)<1 ; \quad F(1,16)<1$; $F(1,16)=2.341$. The treatment means were: high-shock, overtrained, 85.80; highshock, reversal, 70.40; low-shock, overtrained, 64.20; low-shock, reversal, 83.80. Analysis of perseverative error data (number of consecutive incorrect choices after cue reversal) indicated a significant effect due to training $[F(1,16)=10.49, p<.01(\bar{X}=7.3$ for overtrained Ss; $\vec{X}=2.3$ for immediatereversal Ss)]. The effects of shock and the Shock by Training interaction were nonsignificant $[F(1,16)<1 ; F(1,16)<1]$.

The tendency to respond positionally during the first 24 reversal trials was also analyzed. A factorial analysis of number of responses to the preferred position indicated a significant training effect $[\mathrm{F}(1.16)=4.80$, $p<.05 \quad(\bar{X}=14.5$ for overtrained Ss: $\mathrm{X}=17.3$ for immediate-reversal Ss) $]$. As in the perseverative error analysis, the effects of shock and the Shock by Training interaction were nonsignificant $[F(1,16)<1 ; F(1,16)<1]$. Further information regarding the tendency to respond positionally was provided by $x^{2}$ analyses computed for each $S$ during the first 24 reversal trials. Six of the reversal $S$ s demonstrated a significant position preference, while only one overtrained $S$ did. While the trials to criterion data are inconclusive, the perseverative error and position response data are in agreement with the results obtained by Mackintosh (1962) and Reid (1953) in appetitive situations. Level of motivation, as induced by electric shock, was an ineffective variable.

REIFRENCES

KENDLER, H. H, \& LACHMAN, R. Habit reversal as a function of shedulc of reinforcement and drive strength. Joumal of Fxperimental Psychology, 1958, 55, 584-591. MACKINTOSH, N. J. The effects of overtraining on a reversal and a nonreversal shift. Journal of Comparative \& Physiological Psychology. $1962,55,555-559$.

RFID, L. S. The development of noncontinuity behuvior through continuity learning. Journal of 1 yperimental Psychology, 1953, 46. 107-112.

$$
\text { NOTE }
$$

1. Now at the University of Scranton, Suranton, Pennsylvania. 